\section{Entrevista: Hugh Lacey}

Interview: Hugh Lacey
Hugh Lacey é Professor Emérito de Filosofia da Família Scheuer e Pesquisador Sênior na Swarthmore College (Pennsylvania, EUA), onde lecionou por trinta anos, e Pesquisador Colaborador no Projeto Temático "Gênese e significado da tecnociência: relações entre ciência, tecnologia e sociedade", USP/Fapesp. Entre 1969 e 1971 ele foi conferencista no Departamento de Filosofia na Universidade de São Paulo e desde então tem desenvolvido uma intensa interação com universidades brasileiras e institutos de pesquisa, com muitas outras visitas. Alguns dos seus principais interesses de pesquisa são: a interação entre fatos e valores, a relevância do desenvolvimento de alternativas para as práticas tecnocientíficas (agroecologia, por exemplo), o princípio da precaução e os transgênicos. Para conduzir esta entrevista, convidamos a professora Brena Paula Magno Fernandes' ${ }^{1}$ da Universidade Federal de Santa Catarina. Para encerrar essa breve apresentação do entrevistado, 2 é importante mencionar as numerosas publicações do professor Lacey, algumas delas listadas no final da entrevista, como também algumas publicações sobre seu trabalho realizadas por pesquisadores brasileiros. Uma lista mais completa dos seus livros e artigos pode ser encontrada no site da Associação Filosófica Scientiae Studia, $<$ www.scientiaestudia.org.br $>$.
Hugh Lacey is Scheuer Family Professor of Philosophy Emeritus and Senior Research at the Swarthmore College (Pennsylvania, U.S.A.), where he taught for thirty years, and researcher collaborator in the thematic project: "Gênese e significado da tecnociência: relações entre ciência, tecnologia e sociedade", USP/ FAPESP. Between 1969 and 1971 he was a lecturer at the Department of Philosophy of the University of São Paulo and ever since he has developed an intense interaction with Bra-zilian Universities and Research Institutes, with many others visits. Some of his main research interests are: the interplay between facts and values, the relevance of the development of alternatives to technoscientific practices (e.g., agroecology), the precautionary principle and transgenics. To end this brief presentation, it is important to mention Professor Lacey's numerous publications, some of which listed at the end of the interview, as well as some publications on his work made by Brazilian Researchers. A more complete list of this books and articles can be found on the web page of Associação Filosófica Scientiae Studia, <www.scientiaestudia.org.br $>$. 


\section{Revista}

O senhor se formou em matemática e depois migrou para o estudo de história e filosofia da ciência, trabalhando no início de sua carreira principalmente com problemas do mainstream da tradição analítica ('problemas abstratos'). Atualmente, o princípio norteador do seu programa de pesquisa é uma preocupação com problemas muito concretos relacionados à sociedade e às vidas humanas. Isso me leva à primeira pergunta: qual foi a 'virada' da sua trajetória intelectual (se houve alguma)?

\section{Hugh Lacey}

É verdade que minhas teses de mestrado e doutorado e minhas primeiras publicações lidaram com problemas 'abstratos' da filosofia da matemática e da física. Entretanto, não foi um caso de uma 'virada', e muito mais um processo lento de centralizar às minhas preocupações ideias que haviam me interessado por muitos anos. No início, eu estava interessado nas questões de dimensões humanísticas, sociais e políticas da ciência. Escrevi vários artigos em publicações estudantis nesses temas e dei muitas palestras sobre eles. Eu estava especialmente interessado em questões sobre a interação da ciência e a religião (Cristã). Os requisitos para conseguir qualificações formais e para conseguir um cargo acadêmico conduziram ao foco anterior nos problemas 'abstratos'. Enquanto estava na USP, entre 1969 e 1972, comecei a trabalhar em questões de filosofia da psicologia, em grande parte estimulado pelo envolvimento de minha esposa (Maria Inês Rocha e Silva Lacey) em psicologia e o interesse do Instituto de Psicologia da USP de iniciar um curso de pós-graduação em filosofia da psicologia. Usando as ferramentas da filosofia da ciência, escrevi vários artigos sobre o conflito entre a psicologia behaviorista e a cognitiva. Isso me tornou intensamente ciente sobre papel indispensável da ética e dos valores sociais na modelagem de programas de pesquisa em psicologia - muito do meu trabalho posterior na interação entre ciência e valores pode ser visto como uma generalização desse trabalho relacionado à psicologia experimental. Em seguida, durante os anos 1980, Maria Inês e eu ficamos profundamente envolvidos nos movimentos de oposição às guerras apoiadas pelos EUA na América Central, e isso conduziu aos meus estudos, ensino e escritos sobre a Teologia da Libertação da América Latina. A influência da Teoria da Libertação está por trás da minha preocupação atual em perguntar sobre como a ciência deve ser modelada para lidar com os problemas enfrentados pela sociedade e pelas vidas humanas.

\section{Revista}

Em suas publicações recentes (desde 1998 e 1999, por exemplo), o senhor desenvolveu um modelo de interação de atividades científicas e compromissos valorativos. Poderia sintetizar as ideias principais do seu trabalho a respeito da interação de valores cognitivos e sociais nas práticas científicas?

\section{Hugh Lacey}

Os modelos do empirismo lógico e do racionalismo crítico da epistemologia e metodologia da ciência, que dominaram o campo quando eu era um estudante e por algum tempo depois, focavam nas relações entre teoria e dados empíricos. Kuhn introduziu um terceiro termo, paradigma, em discussões de metodologia. No meu modelo é central uma modificação da noção de Kuhn, que eu chamo de 'estratégia'. Os principais papéis de uma estratégia são restringir os tipos de teorias que podem ser consideradas na pesquisa e fornecer critérios para a seleção dos tipos de dados empíricos que podem ser procurados e registrados para o fim de avaliar teorias - onde a teoria fornece entendimento de algum domínio de fenômeno ou outro. O que é avaliado é se uma teoria é ou não confirmada dentro de um domínio específico de fenômeno. Essa avaliação depende somente de o quão adequadamente a teoria se encaixa nos dados empíricos, à luz de critérios cognitivos (epistêmicos) específicos que, seguindo Kuhn, eu chamo de 'valores cognitivos'.

Eu tenho argumentado que valores cognitivos são distintos de outros tipos de valores (incluindo valores éticos e sociais). Entretanto, sustento que valores éticos e socais possuem um papel legitimado (e provavelmente indispensável) em conexão à estratégia a ser adotada em um projeto de pesquisa. Não há só uma metodologia científica; ao invés disso, a questão metodológica fundamental é a escolha da estratégia. Essa escolha varia propriamente com as características do objeto de investigação; as mesmas estratégias não podem lidar adequadamente, por exemplo, 
com estruturas moleculares de sementes e com seu papel em agroecossistemas sustentáveis (para usar um exemplo sobre o qual já escrevi detalhadamente). São os valores éticos e sociais que motivam, dando prioridade para um objeto particular de investigação em preferência a outro, e assim para a estratégia que será adotada no projeto de pesquisa subsequente. Afirmo que existem relações de reforço mútuo entre adotar uma estratégia e manter certos valores ético/sociais. Frequentemente, os valores que motivam a adoção de uma estratégia particular são os mesmos que informam os interesses que são atendidos quando os resultados da pesquisa são aplicados.

Algumas vezes, eu destaco três 'momentos' da atividade científica: (1) escolha da estratégia, (2) avaliação da teoria, (3) aplicação de resultados científicos. De acordo com o meu modelo, existem papéis de legitimação para valores éticos e sociais, não somente em (3), mas também em (1) - mas em (2) apenas os valores cognitivos têm um papel legítimo na avaliação de teorias. Assim, o modelo preserva a possibilidade de objetividade do conhecimento científico, enquanto reconhece um destino para a crítica ética e política da pesquisa científica. Isto ocorre porque o fato de que certos resultados sejam objetivamente confirmados não implica que eles possam ser aplicados a serviço de interesses modelados por qualquer configuração de valores éticos e sociais.

\section{Revista}

Um dos argumentos-chave do seu modelo é o reforço mútuo entre um valor social específico - o ideal baconiano de controle da natureza e a ciência moderna. O senhor poderia explicar essa conexão com mais detalhes?

\section{Hugh Lacey}

A pesquisa científica moderna tendeu a adotar virtualmente apenas variedades de estratégias que se encaixem (no que agora eu chamo) de abordagem descontextualizada. (Em documentos anteriores me referi a elas como 'estratégias materialistas'). Sob essas estratégias, teorias são restringidas para que possam representar a estrutura subjacente, a interação, o processo e a lei dos fenômenos, dissociadas de seus contextos ecológico, social e humano.

A pesquisa conduzida sob estas estratégias é que prontamente leva à inovação tecnológica, a realização social concreta da ideia baconiana de controle da natureza. Claramente, se alguém está engajado em uma pesquisa cuja finalidade é fazer descobertas capazes de levar à inovação tecnológica, é adequado adotar estratégias da abordagem descontextualizada. Mas essas estratégias por si próprias não nos tornam capazes de investigar adequadamente os riscos da implementação de tais inovações, e a explorar as possibilidades de alternativas práticas que não estão enraizadas na inovação tecnológica. (Para entender as possibilidades da agricultura transgênica, estratégias descontextualizadas são essenciais; para explorar as possibilidades da agricultura agroecológica, outras estratégias também devem ser adotadas.) Tenho argumentado que podemos explicar o uso quase exclusivo de estratégias que se enquadram na abordagem descontextualizada da ciência moderna fazendo referência às relações de reforço mútuo que existem entre a adoção dessas estratégias e manter (o que eu chamo) os valores do progresso tecnológico, o que pode ser visto como uma atualização da valoração baconiana do controle da natureza. Note que isso ilustra bem a característica do meu modelo de preservação dos resultados objetivos (teorias científicas modernas frequentemente representam o conhecimento objetivo da estrututra subjacente/interação/processo/lei de domínios importantes de fenômenos!), enquanto permite certos tipos de crítica política como legítimas. Alguém pode criticar o uso quase exclusivo de estratégias de acordo com a abordagem descontextualizada sem com isso questionar a objetividade dos seus resultados confirmados.

\section{Revista}

Progressos científicos tornaram possível o progresso tecnológico, que hoje é um pré-requisito integral para o crescimento econômico (no âmbito do capitalismo). Por que o senhor questiona que a tecnociência pode ter enfraquecido os valores democráticos?

\section{Hugh Lacey}

Atualmente, a tecnociência está se desenvolvendo em associação próxima com interesses entre os quais o crescimento econômico é a consideração primária. As estratégias adotadas na pesquisa tecnocientífica atual têm uma relação de reforço mútuo não somente com os valores do progresso tecnológico, mas também com valores que dão a maior importância ao crescimento econômico. 
É isto que ameaça os valores democráticos - por ser a pesquisa científica cada vez mais colocada sob o controle das corporações (agrobusiness, corporações farmacêuticas e de energia etc.) e agências de governo que são sensíveis aos interesses corporativos. (Tem sido dito que a ciência está se transformando em 'ciência do interesse privado'.) Isso quer dizer que a pesquisa que é muito importante para fortalecer os valores democráticos não está sendo conduzida, ou que recursos inadequados estão disponíveis a ela. Por exemplo, segurança alimentar é essencial para o bom funcionamento da democracia - mas a crise mundial de alimentos do ano passado mostrou definitivamente que a dominação da oferta de alimentos pelo agrobusiness, que é responsável por fazer a agricultura dependente de inovações tecnocientíficas, como transgênicos, não produz segurança alimentar. Muitos movimentos sociais estão propondo que programas de 'soberania alimentar', nos quais a agroecologia é desenvolvida e usada muito mais extensivamente, estabeleçam o caminho para a produção da segurança alimentar. A inovação tecnocientífica pode certamente tomar parte nestes projetos, apesar de eles não estarem primordialmente baseados nela. A pesquisa necessária para o fortalecimento dos projetos de soberania alimentar (e para testar seu potencial total) não é capaz de obter os recursos adequados enquanto a ciência do 'interesse privado' é dominante. Então, não quero dizer que a tecnociência per se enfraquece os valores democráticos, mas que a ciência e a tecnociência dominadas pelos interesses do crescimento econômico (abstraindo valores como segurança alimentar para todos) os ameaçam.

\section{Revista}

O senhor tem defendido a ideia de que novas formas de pesquisa científica não necessariamente conectadas com o controle da natureza devem ser promovidas, em atenção ao pluralismo do sistema de valores existente em uma sociedade. Poderia explicar essa proposta e quais seriam suas principais dificuldades práticas?

\section{Hugh Lacey}

O exemplo da 'soberania alimentar' é um caso pertinente. A insegurança alimentar de vastos números de pessoas e nações não tem sido adequadamente tratada pelas práticas e políticas agrícolas predominantes na atualidade - que são informadas por resultados científicos (que geraram os transgênicos, por exemplo) obtidos sob estratégias com relações de reforço mútuo com valores que dão a maior importância ao crescimento econômico, embora esteja claro que o crescimento econômico não se 'traduz', por exemplo, em segurança alimentar para todos. A agroecologia objetiva investigar as possibilidades dos agroecossitemas em termos de sua contribuição simultânea à produtividade, à sustentabilidade, à preservação da biodiversidade, à saúde social e ao favorecimento dos interesses e fortalecimento dos valores das comunidades locais. Como o contexto é essencial a esse tipo de pesquisa, ela não se coaduna à abordagem descontextualizada (embora possa livremente usar o conhecimento objetivo obtido dentro da abordagem descontextualizada). Outras estratégias são também necessárias para conduzir essa pesquisa. Subordinar o crescimento econômico à segurança alimentar para todos motiva o engajamento em pesquisas desse tipo.

As principais dificuldades diante desta ideia são: primeiro, que o mainstream da ciência não pensa em pesquisa científica simplesmente como pesquisa empírica que possa produzir conhecimento confirmado objetivamente. Ao invés disso, ele tende a identificar a pesquisa científica com a pesquisa conduzida no âmbito da abordagem descontextualizada, então ele (impropriamente) rejeita a credencial científica de abordagens alternativas e, de modo mais geral, não leva a sério a ideia de que pode haver um pluralismo de estratégias frutíferas. Em segundo lugar, as abordagens alternativas funcionam contra os poderosos interesses da ciência do 'interesse privado', que estão por trás dela.

\section{Revista}

De acordo com a sua experiência pessoal (morar nos EUA e possuir um intenso contato com um país 'periférico'), o senhor acredita que a América Latina tem um papel específico a desempenhar ao apresentar alternativas de pesquisa à corrente convencional?

\section{Hugh Lacey}

Eu seguramente acho que movimentos sociais em áreas empobrecidas do mundo (incluindo a América Latina) têm esse papel, pois é entre elas que valores como segurança alimentar (e participação democrática popular) são mais prováveis de ficar em primeiro plano. A pesquisa 
ligada à 'soberania alimentar', por exemplo, tem uma importância particular entre pessoas que estão vivenciando insegurança alimentar. Elas possuem a percepção clara de que os métodos atuais estão falhando, e elas precisam de uma alternativa urgentemente. Assim, não é surpreendente que os movimentos sociais que criaram a Via Campesina tenham alcançado a liderança em fazer propostas para a implementação da soberania alimentar - e demandado recursos para a condução de mais pesquisas em campos como a agroecologia.

Entretanto, eu não acho que se deva exagerar nesse papel para os movimentos sociais. Outros podem compartilhar também os mesmos valores, e a sustentabilidade - um valor altamente sustentado dentro dos movimentos sociais, e importante para os projetos científicos alternativos - é sem dúvida amplamente compartilhada. Além disso, o engajamento nas práticas alternativas deve ganhar apoio de valores tradicionais centrais da ciência moderna, como: ser parte do patrimônio compartilhado da humanidade e também a objetividade. A respeito da objetividade, a menos que as possibilidades dos agroecossistemas sustentáveis sejam investigadas (sob as estratégias apropriadas), a reivindicação dos portavozes da ciência de que não existem possibilidades sérias fora da trajetória da tecnociência será necessariamente não objetiva.

\section{Notas}

1 Professora substituta do Departamento de Economia da Universidade Federal de Santa Catarina (UFSC). Atuou como integrante na pesquisa "Ciência moderna, tecnologia e controle: uma extensão da crítica de Hugh Lacey ao caso da economia", financiada pelo CNPq, entre 2005 e 2007.

$2 \mathrm{O}$ texto original em inglês desta entrevista pode ser consultado no site www.revista.epsjv.fiocruz.br.

\section{Algumas publicações de Hugh Lacey:}

LACEY, H. Valores e atividade científica. São Paulo: Discurso Editorial, 1998.
Is science value free? Values and scientific understanding. Londres: Routledge, 1999.

- As formas nas quais as ciências são e não são livres de valores. Crítica, Londrina, v. 6 , n. 21, p. 89-111, 2000.

. Psicologia experimental e natureza humana. Florianópolis: Editora da Universidade Federal de Santa Catarina, 2001.

Tecnociência e os valores do Fórum Social Mundial. In: LOUREIRO, J. M.; CEVASCO, M. E.; CORRÊA LEITE, J. (eds.), O espírito de Porto Alegre, Porto Alegre: Ed. Paz e Terra, 2000.

Existe uma distinção relevante entre valores cognitivos e sociais?. 2003a. Scientiae Studia, v. 1, n. 2, p. 121-49. Disponível em: $<$ www.scientiaestudia.org.br/revista/PDF/01_ 02_01_Lacey.pdf $>$

A ciência e o bem-estar humano: uma nova maneira de estruturar a atividade científica". In: SANTOS, B. de S. (ed.). Conhecimento prudente para uma vida decente: um discurso sobre as ciências revisitado. Porto: Afrontamento, 2004, p. 471-493, 2003b.

A controvérsia sobre os transgênicos: questões éticas e científicas. Aparecida, SP: Ideias e Letras, 2006a.

- O princípio de precaução e a autonomia da ciência. 2006b. Scientia Studia v. 4, n. 3, p. 373392. Disponível em: <www.scientiaestudia.org. br/revista/PDF/04_03_02.pdf >

Há alternativas ao uso dos transgênicos? Novos estudos - Cebrap, n. 78, p. 31-39, 2007. Disponível em: <www.scielo.br/pdf/nec/n78/05.pdf>

Valores e atividade científica 1. São Paulo: Associação Filosófica Scientiae Studia e Editora 34, 2008a. (Second edition of 1998).

- Crescimento econômico, meio ambiente e sustentabilidade social: a responsabilidade dos cientistas e a questão dos transgênicos. In: DUPAS, Gilberto (ed.). Meio-ambiente e crescimento econômico: tensões estruturais, São Paulo: Editora Unesp, p. 91-130, 2008b. 
Aspectos cognitivos e sociais das práticas científicas. Scientiae Studia 6, v. 1, p. 83-96, 2008c.

Ciência, respeito à natureza e bem-estar humano. Scientiae Studia 8, n. 3, p. 297-327, 2008d.

Valores e atividade cientifica 2. São Paulo: Associação Filosófica Scientiae Studia e Editora 34, 2009. (Second edition of 1998).

\section{Publicações sobre o modelo de Hugh Lacey:}

FERNANDEZ, B. Isenção ou inserção de valores na ciência? A posição crítica de Hugh Lacey. 2003. Cadernos de Pesquisa Interdisciplinar em Ciências Humanas (UFSC), Florianópolis, n. 49, p. 1-16. Disponível em: <www.cfh.ufsc.br/ dich/Texto Caderno49.pdf $>$

Retomando a discussão sobre o papel dos valores na ciência: a teoria econômica dominante é (pode ser) axiologicamente neutra?. 2006. Episteme (Porto Alegre), v. 23, p. 151-176. Disponível em: <www.ilea.ufrgs.br/episteme/portal/ pdf/numero23/episteme23_fernandez.pdf $>$

A epistemologia de Hugh Lacey em diálogo com a economia feminista: neutralidade, objetividade e pluralismo. 2008. Revista Estudos Feministas, v. 16, n. 2, p. 359-385. Disponível em: $<$ www.scielo.br/pdf/ref/v16n2/04.pdf >

OLIVEIRA, M. B. A epistemologia engajada de Hugh Lacey. Manuscrito, v. 21, n. 2, p. 113-135, 1998. Disponível em: <www2.fe.usp.br/ mbarbosa/ hlaceyl.pdf>

. A epistemologia engajada de Hugh Lacey II", Manuscrito 23, n. 1, p. 185-203, 2000. Disponível em: <www2.fe.usp.br/ mbarbosa/hlacey2.pdf>

Science and the values of popular movements. Trans/Form/Ação, v. 27, n. 1, p. 133-147, 2004. Disponível em: <www.scielo.br/pdf/trans/ v27nl/a10v27n1.pdf $>$

OLIVEIRA, M. B.; FERNANDEZ, B. Hempel, Semmelweis e a verdadeira tragédia da febre puerperal. Scientiae Studia, v. 5, n. 1, p. 49-79, 2007.
Disponível em: <www.scientiaestudia.org.br/ revista/PDF/05_01_03.pdf>

REGNER, A. C. Ciência e valores: retomando o fôlego da questão. Episteme, Porto Alegre, n. 10, p. 125-134, 2000. Disponível em: <www.ilea. ufrgs.br/episteme/portal/pdf/numero10/episte mel0_resenha_regner.pdf $>$ 